\title{
Experience of subjective symptoms in Euthymic Bipolar Dis- order and remitted Schizophrenia patients and its relation with Quality of Life and Social Functioning
}

\author{
Manish Kumar', Vinod K. Sinha ${ }^{2}$, A. Mondal ${ }^{3}$ \\ ${ }^{1}$ RMO cum Clinical Tutor, Dept. of Psychiatry, Nilratan Sircar Medical College, Kolkata, ${ }^{2}$ Professor of \\ Psychiatry \& Chief of Center for Child and Adolescent Psychiatry, Central Institute of Psychiatry, Ranchi, ${ }^{3}$ \\ Ph.D. Scholar, Dept. of Clinical Psychology, RINPAS, Kanke, Ranchi.
}

\section{ABSTRACT}

Introduction : Subjective experience means subtle, not yet psychotic abnormalities of experience that might be present during remitted phase and also in prodromal phase of schizophrenia and might be accurately efficient in identifying individual at risk of eminent psychosis. Most studies on the subjective experiences have been conducted in schizophrenia and to a lesser extent in affective disorders.Only few studies have compared subjective experience of patients with bipolar disorder with the patients with schizophrenia, and the results were inconsistent. These subjective experiences may be related to distorted cognitive functions in these patients. Cognitive deficits are a major contributor to the functional and social impairment suffered by these patients and have been noted to have more of an impact on the daily lifeand overall quality of life of these patients.

Objective : The current study aims at comparing the subjective experience in schizophrenia and bipolar patients, in order to elucidate the difference between the two groups and this study was further extended to measure the effect of subjective experiences on one's occupational and social functioning.

Method : The study was conducted on 30 euthymic bipolar patients and 30 remitted schizophrenic patients diagnosed as per ICD-10. The patients were rated for on Frankfurt Complaint Questionnaire (FCQ-24) and Symptoms check list 90 revised (SCL90-R) to assess subjective symptoms. Work and social adjustment scale, functional status questionnaire and WHO-QOL BREF were administered one by one on the patient.

Results : Diagnosis of schizophrenia was associated with elevated score on FCQ as compared to bipolar disorders mainly in the areas of perception, thought, language and motility as well as total FCQ scores. FCQ scores correlated negatively with scores on functional status questionnaire, positively with work and social adjustment scale and negatively with all the domains of WHOQOL BREF except environment/financial resources.

Conclusion : These findings, in conjunction with those from other, methodologically similar studies, suggest that certain anomalies of subjective experience aggregate significantly in schizophrenia when compared with bipolar disorders and adversely affected their functioning and quality of life

Keywords : subjective symptoms, euthymic bipolar disorder, remitted schizophrenia

\section{Corresponding Author :}

Dr. Manish Kumar, RMO cum Clinical Tutor, Dept. of Psychiatry, Nilratan Sircar Medical College, Kolkata, India

Email : manishonline777@gmail.com. 


\section{Experience of subjective symptoms in Euthymic Bipolar and remitted Schizophrenia}

\section{INTRODUCTION}

Subjective experience means subtle, not yet psychotic abnormalities of experience that might be present during remitted phase and also in prodromal phase of schizophrenia and might be accurately efficient in identifying individual at risk of eminent psychosis (Parnas, 2003). Abnormal subjective experiences, other than delusions and hallucinations are becoming accepted as having important implications for the comprehension and treatment of schizophrenic disorders (Arduini, 2002). These experiences include a great variety of cognitive dysfunction complaints about attention, perception, memory, thinking, language, movement and emotion. Recently, there has been renewed interest in the study of subjective symptoms. Apart from schizophrenic patients, bipolar patients also experience certain subjective symptoms in their euthymic state. They often experience subtle cognitive impairment and functional disturbances during their euthymic states. To date, little attention has been paid to subjective cognitive impairment in bipolar disorder (Joe et al., 2008). These subjective experiences may be related to distorted cognitive functions in these patients.

It is generally accepted that cognitive dysfunction persists in the remitted schizophrenics (Parnas, 2003). In contrast, more recently, however, the number of studies on the persistence of cognitive and perceptual distortion in bipolar patients has increased (Cavanagh, 2002). To our knowledge, there are few studies to compare subjective experience of patients with bipolar disorder with the patients with schizophrenia, and the results were inconsistent (Arduini, 2002). Joe et al (2008) compared experience of subjective symptoms in normal control, euthymic bipolar patients and remitted schizophrenia patients. The scores were significantly higher in the bipolar group than in the normal control group, and they were similar between the bipolar group and schizophrenia group. Depression, anxiety, phobic anxiety, and paranoid ideation subscale scores of the bipolar group were similar to those of the normal control group, and they were lower than those of the schizophrenia group. However, studies comparing subjective experiences in schizophrenic and affective disorders have reached inconclusive results.

As because cognitive ability is critical in interpersonal relationships, social skills and social activities, so this study was further extended to measure the effect of subjective experiences on these areas. Chapman (1966) interviewed 40 schizophrenia inpatients with a maximum duration of illness of 3 years to examine changes in subjective experience in early stages of the disease. He interpreted these cognitiveperceptual phenomena as primary, while affective symptoms (anxiety, depression), social withdrawal, and certain odd behaviors were considered secondary reactions. Thus, in earlier phases, when developing illness becomes obvious to others, then negative coping strategies are employed (eg, social withdrawal or avoidance of certain situations/ activities). Addington\& Addington, 1999, using the Social Functioning Scale (SFS), the Quality of Life Scale (QLS), did a study on 80 schizophrenia outpatients where an association between certain aspects of distorted cognitive functioning and social functioning was found. In another study by Hofer et al. (2005) on 60 schizophrenia outpatients, associations have been found between the severity of cognitive deficits of subjective experiences and social dysfunction, impairments in independent living, occupational limitations, and disturbances in quality of life (QOL). In euthymic bipolar disorder also, experience of subjective symptoms often leads to intereference to other symptoms like work and social functioning, quality of life (Tsuang et al., 1979).

The aim of the present study was therefore to evaluate and compare the subjective experience in schizophrenia and bipolar patients and to elucidate the relationship between subjective experiences, social adjustment and quality of life in schizophrenic and bipolar patients. 


\section{Experience of subjective symptoms in Euthymic Bipolar}

and remitted Schizophrenia

\section{METHODOLOGY}

\section{SAMPLE}

Thirty euthymic bipolar patients (euthymia was defined as YMRS score $\leq 12 \&$ HRSD cutoff values $\leq 7$ ), 30 remitted schizophrenic patients (PANSS score $<60$ and the mean of any three sub scale of PANSS was not greater than 3) diagnosed as per ICD-10 DCR were selected from the patients coming to OPD or admitted in the Central Institute of Psychiatry, Ranchi.

\section{PROCEDURE}

Thirty Euthymic bipolar patients and 30 remitted schizophrenia patients as per ICD 10 meeting the inclusion-exclusion criteria were selected for purpose of the study. Written informed consent was taken after explaining the procedure to the patients in detail. Socio-demographic data was collected and then the patients were assessed using the above mentioned scales in OPD or in admitted patients. The collected data were then tabulated, analyzed and assessed properly with appropriate use of statistics.

\section{STATISTICAL ANALYSIS}

The statistical analysis was done with the help of Statistical Package for Social Sciences-13 (SPSS-13). For measuring the difference amongst various socio demographic and clinical variables, chi square was applied for discrete variables. Independent $t$ test was used to examine the difference between the schizophrenia and bipolar groups. For correlation parametric test Pearson's correlation coefficient - (r) was used.

Table1 : Comparison of Ten Phenomenological Subscale of Frankfurt Complaint Questionnaire (FCQ-24) Between the Two Groups

\begin{tabular}{|l|c|c|c|c|}
\hline \multicolumn{1}{|c|}{ Subjects Subscales } & $\begin{array}{c}\text { Mood disorders } \\
(\mathrm{N}=30) \\
\text { Mean } \pm \text { SD }\end{array}$ & $\begin{array}{c}\text { Schizophrenia } \\
(\mathrm{N}=30) \\
\text { Mean } \pm \text { SD }\end{array}$ & df & 't' value \\
\hline FCQ total & $38.57 \pm 1.60$ & $47.17 \pm 8.31$ & 58 & $-3.893^{* *}$ \\
\hline Loss of control & $5.50 \pm .29$ & $6.37 \pm 1.60$ & 58 & $-2.084^{*}$ \\
\hline Simple perception & $1.13 \pm .06$ & $1.56 \pm .56$ & 58 & $-3.568^{* *}$ \\
\hline Complex perception & $2.56 \pm .13$ & $3.20 \pm 1.06$ & 58 & $-2.692^{* *}$ \\
\hline Language & $6.10 \pm .33$ & $7.60 \pm 2.19$ & 58 & $-2.868^{* *}$ \\
\hline Thought & $5.26 \pm .30$ & $7.66 \pm 1.84$ & 58 & $-5.298^{* *}$ \\
\hline Memory & $2.86 \pm .18$ & $3.23 \pm 1.16$ & 58 & -1.304 \\
\hline Motility & $1.43 \pm .11$ & $1.83 \pm .53$ & 58 & $-2.670^{* *}$ \\
\hline Lack of automatism & $6.60 \pm .29$ & $7.57 \pm 1.59$ & 58 & $-2.339^{*}$ \\
\hline Anhedonia anxiety & $3.50 \pm .19$ & $3.93 \pm 1.17$ & 58 & -1.492 \\
\hline Sensory Overstimulations & $3.60 \pm .26$ & $4.20 \pm 1.03$ & 58 & -1.845 \\
\hline
\end{tabular}

* significant at 0.05 level, ** significant at 0.01 level 


\section{Experience of subjective symptoms in Euthymic Bipolar and remitted Schizophrenia}

\section{RESULTS}

The two groups, euthymic bipolar and remitted schizophrenia were compared on socio-demographic variables like age, sex, education, occupational status, marital status, family type, economic status and religion. However, no significant difference has been found between the two groups. On comparing the clinical variables between the two

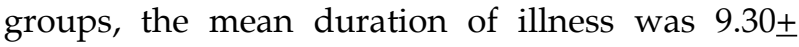
$4.84(\mathrm{SD})$ years in bipolar group and $7.87 \pm 4.59$ (SD) years in schizophrenia group with no significant difference among both the groups. Mean number of hospitalization was $1.00 \pm 1.08$ (SD) in bipolar group and $0.57 \pm 7.28$ (SD) in schizophrenia group with no significant difference among both the groups. Duration of remission was $26.36 \pm 22.3$ (SD) years in bipolar group as compared to $20.80 \pm 22.52$ (SD) years in schizophrenia group but this too also has not reached statistical significance. In regard to objective pathology of the two groups, mean YMRS score was $1.50 \pm 1.69$ (SD) and HDRS score was 2.57 $\pm 1.86(\mathrm{SD})$ in bipolar group. Table 1 shows the comparison of FCQ-24 score between two groups where most of the phenomenological dimensions of FCQ-24 showed significant difference between the two groups except on memory $(p=0.198)$ and anhedonia anxiety ( $\mathrm{p}=0.141$ ). Patient with schizophrenia, when compared with bipolar affective disorder, were found to show higher score in phenomenological areas of loss of control $(\mathrm{p}=0.042)$, simple perception $(\mathrm{p}=0.001)$, complex perception $(\mathrm{p}=0.009)$, language $(\mathrm{p}=0.006)$, thought $(\mathrm{p}=0.000)$, motility $(\mathrm{p}=0.010)$ and lack of automatism ( $\mathrm{p}=0.023)$; further schizophrenia group had shown a significantly higher FCQ-24 total score.
Table 2 shows the comparison of SCL-90R score between the two groups where patients with schizophrenia when compared with bipolar affective disorder, were found to show higher score in the dimensions of obsessive compulsive $(\mathrm{p}=0.008)$, depression $(\mathrm{p}=0.005)$, anxiety $(\mathrm{p}=0.003)$, phobic anxiety $(\mathrm{t}=2.444, \mathrm{p}=0.018)$, paranoid ideation $(\mathrm{p}=0.001)$ and psychoticism $(\mathrm{p}=0.000)$. It had not reached statistical significance in the dimensions of somatization $(p=1.00)$, interpersonal sensitivity $(\mathrm{p}=0.350)$ and anger hostility $(\mathrm{p}=0.071)$.

Table 3 shows correlation of the scores on subscales of FCQ-24 with scores on functional status questionnaire. All the subscale of FCQ-24 correlated negatively with the functional status questionnaire total score. Complex perception, language, thought, memory, motility and lack of automatism were negatively correlated at the level of $\mathrm{p}<0.01$ while loss of control, simple perception, anhedonia, anxiety and sensory overstimulation were correlated at the level of $p<0.05$. There was no correlation between any of the subscales of FCQ and basic ADL. Intermediate ADL was correlated negatively with complex perception, thought, memory and motility at the level of $p<0.01$ and with lack of automatism and anhedonia anxiety at the level of $p<0.05$. Complex perception, language, thought, memory, motility, lack of automatism and anhedonia anxiety correlated negatively with mental health at the level of $\mathrm{p}<0.01$. Language, memory, anhedonia anxiety correlated negatively with work performance at the level of $\mathrm{p}<0.01$ whereas thought correlated negatively at the level of $p<0.05$. Significant correlation was found between all the subscale of FCQ-24 except loss of control and sensory overstimulation with social activities. 


\section{Experience of subjective symptoms in Euthymic Bipolar and remitted Schizophrenia}

Table 2 : Comparison of Subscale Score of SCL-90R Between the Two Groups

\begin{tabular}{|l|l|c|c|c|c|}
\hline $\begin{array}{l}\text { S } \\
\text { No }\end{array}$ & \multicolumn{1}{|c|}{ Subscales } & $\begin{array}{c}\text { Bipolar disorders } \\
(\mathrm{N}=30) \\
\text { Mean } \pm \text { SD }\end{array}$ & $\begin{array}{c}\text { Schizophrenia } \\
(\mathrm{N}=30) \\
\text { Mean } \pm \text { SD }\end{array}$ & df & 't' value \\
\hline SCL Total & $37.77 \pm 11.113$ & $50.87 \pm 14.486$ & 58 & .000 \\
\hline 1 & Somatization & $3.83 \pm 2.230$ & $3.83 \pm 3.097$ & 58 & .000 \\
\hline 2 & Obsessive Compulsive & $5.30 \pm 2.168$ & $6.63 \pm 1.564$ & 58 & $2.732^{* *}$ \\
\hline 3 & Interpersonal sensitivity & $4.50 \pm 2.162$ & $5.03 \pm 2.220$ & 58 & .943 \\
\hline 4 & Depression & $6.07 \pm 3.205$ & $8.33 \pm 2.857$ & 58 & $2.892^{* *}$ \\
\hline 5 & Anxiety & $3.83 \pm 2.001$ & $5.43 \pm 1.942$ & 58 & $3.142^{* *}$ \\
\hline 6 & Anger hostility & $3.93 \pm 1.964$ & $4.90 \pm 2.107$ & 58 & 1.838 \\
\hline 7 & Phobic anxiety & $2.03 \pm 1.450$ & $3.10 \pm 1.900$ & 58 & $2.444^{*}$ \\
\hline 8 & Paranoid ideation & $2.47 \pm 1.383$ & $3.97 \pm 1.847$ & 58 & $3.560^{* *}$ \\
\hline 9 & Psychotism & $3.00 \pm 1.554$ & $5.50 \pm 1.540$ & 58 & $4.459^{* *}$ \\
\hline
\end{tabular}

* Correlation is significant at 0.05 level ${ }^{* *}$ Correlation is significant at 0.01 level

Finally thought, memory, anhedonia anxiety and sensory overstimulation were also negatively correlated with quality of social interaction $(\mathrm{p}<0.05)$.

Table 4 shows correlation of the scores on subscales of FCQ-24 with scores on work and social adjustment scale. All the subscale of FCQ24 correlated positively with the work and social adjustment scale score $(p=0.000)$. Simple perception was correlated positively with work and social adjustment scale score at $\mathrm{p}<0.05$ whereas all other dimensions of FCQ-24 correlated with work and social adjustment scale at the level of $p<0.01$. Table 5 shows correlation of the scores on subscales of FCQ24 with scores on WHO-QOL BREF. FCQ-24 total score didn't correlate with environment/financial resources while it correlated negatively with overall perception of QOL, physical health, psychological and social relationship at $\mathrm{p}<0.01$ and with overall perception of health at $\mathrm{p}<0.05$. Any of the subscale of FCQ-24 didn't correlate with environmental/ financial resources except simple perception which correlated negatively at $\mathrm{p}<0.05$. Simple perception and memory correlated with overall perception of QOL at $\mathrm{p}<0.05$ while loss of control, complex perception language though and lack of automatism correlated at $\mathrm{p}<0.01$. 


\section{Experience of subjective symptoms in Euthymic Bipolar and remitted Schizophrenia}

Table 3 : Relationship of scores of subscales of FCQ-24 with scores of functional status questionnaire in both the groups (r)

\begin{tabular}{|c|l|c|c|c|c|c|c|c|}
\hline \multirow{2}{*}{ S. No. } & \multicolumn{1}{|c|}{$\begin{array}{c}\text { Frankfurt } \\
\text { complaint } \\
\text { questionnaire }\end{array}$} & $\begin{array}{c}\text { Functional } \\
\text { status } \\
\text { questio- } \\
\text { nnaire }\end{array}$ & $\begin{array}{c}\text { Basic } \\
\text { ADL }\end{array}$ & $\begin{array}{c}\text { Interme- } \\
\text { diate ADL }\end{array}$ & $\begin{array}{c}\text { Mental } \\
\text { health }\end{array}$ & $\begin{array}{c}\text { Work } \\
\text { performance }\end{array}$ & $\begin{array}{c}\text { Social } \\
\text { activi-ties }\end{array}$ & $\begin{array}{c}\text { Quality } \\
\text { of social } \\
\text { interac-tion }\end{array}$ \\
\hline \multicolumn{2}{|l|}{ FCQ total } & $-.599^{* *}$ & -.006 & $-.386^{* *}$ & $-.553^{* *}$ & $-.409^{* *}$ & $-.515^{* *}$ & $-.372^{* *}$ \\
\hline 1 & loss of control & $-.287^{*}$ & -.248 & -.186 & -.184 & -.157 & -.218 & -.140 \\
\hline 2 & simple perception & $-.276^{*}$ & -.013 & -.167 & -.177 & -.076 & $-.304^{*}$ & -.231 \\
\hline 3 & $\begin{array}{l}\text { complex } \\
\text { perception }\end{array}$ & $-.427^{* *}$ & .083 & $-.480^{* *}$ & $-.379^{* *}$ & -.222 & $-.381^{* *}$ & -.249 \\
\hline 4 & Language & $-.448^{* *}$ & -.061 & -.201 & $-.459^{* *}$ & $-.412^{* *}$ & $-.385^{* *}$ & -.176 \\
\hline 5 & Thought & $-.504^{* *}$ & .051 & $-.388^{* *}$ & $-.475^{* *}$ & $-.269^{*}$ & $-.451^{* *}$ & $-.376^{* *}$ \\
\hline 6 & Memory & $-.608^{* *}$ & .093 & $-.387^{* *}$ & $-.655^{* *}$ & $-.476^{* *}$ & $-.530^{* *}$ & $-.328^{*}$ \\
\hline 7 & Motility & $-.394^{* *}$ & .009 & $-.356^{* *}$ & $-.363^{* *}$ & -.235 & $-.410^{* *}$ & -.218 \\
\hline 8 & $\begin{array}{l}\text { lack of } \\
\text { automatism }\end{array}$ & $-.376^{* *}$ & .194 & $-.320^{*}$ & $-.330^{* *}$ & -.244 & $-.289^{*}$ & -.218 \\
\hline 9 & $\begin{array}{l}\text { anhedonia } \\
\text { anxiety }\end{array}$ & $-.514^{*}$ & .064 & $-.312^{*}$ & $-.513^{* *}$ & $-.334^{* *}$ & $-.490^{* *}$ & $-.370^{* *}$ \\
\hline 10 & $\begin{array}{l}\text { sensory } \\
\text { overstimulations }\end{array}$ & $-.311^{*}$ & -.195 & -.216 & -.203 & -.137 & -.184 & $-.264^{*}$ \\
\hline
\end{tabular}

* Correlation is significant at 0.05 level, ${ }^{* *}$ Correlation is significant at 0.01 level

Table 4 : Relationship of scores of subscales of FCQ-24 with scores of work and social adjustment scale (r)

\begin{tabular}{|c|l|c|c|}
\hline \multirow{2}{*}{ S No } & \multicolumn{1}{|c|}{ FCQ } & Correlation coefficient $(\mathrm{r})$ & \multirow{2}{*}{$\mathrm{p}$} \\
\cline { 3 - 4 } & & Work and social adjustment scale & .000 \\
\hline 1 & FCQ total & $.686^{* *}$ & .004 \\
\hline 2 & Loss of control & $.370^{* *}$ & .045 \\
\hline 3 & Simple perception & $.260^{*}$ & .000 \\
\hline 4 & Complex perception & $.453^{* *}$ & .000 \\
\hline 5 & Language & $.525^{* *}$ & .000 \\
\hline 6 & Thought & $.536^{* *}$ & .000 \\
\hline 7 & Memory & $.586^{* *}$ & .000 \\
\hline 8 & Motility & $.446^{* *}$ & .001 \\
\hline 9 & Lack of automatism & $.402^{* *}$ & .000 \\
\hline 10 & Anhedonia anxiety & $.572^{* *}$ & .005 \\
\hline 11 & Sensory overstimulations & $.360^{* *}$ & \\
\hline
\end{tabular}




\section{Experience of subjective symptoms in Euthymic Bipolar and remitted Schizophrenia}

Table 5 : Relationship of scores of subscales of FCQ-24 with scores of WHO-QOL: Correlation

\begin{tabular}{|c|l|c|c|c|c|c|c|}
\hline \multirow{2}{*}{ S.N. } & \multirow{2}{*}{$\begin{array}{c}\text { Frankfurt complaint } \\
\text { questionnaire }\end{array}$} & $\begin{array}{c}\text { Overall } \\
\text { perce-ption } \\
\text { of QOL }\end{array}$ & $\begin{array}{c}\text { Overall percep- } \\
\text { tion of health }\end{array}$ & $\begin{array}{c}\text { Physical } \\
\text { Health }\end{array}$ & $\begin{array}{c}\text { Psycho- } \\
\text { logical }\end{array}$ & $\begin{array}{c}\text { Social } \\
\text { Relation- } \\
\text { ship }\end{array}$ & $\begin{array}{c}\text { Environment/ } \\
\text { Financial } \\
\text { resources }\end{array}$ \\
\hline \multicolumn{2}{|l|}{ FCQ Total } & $-.381^{* *}$ & $-.326^{*}$ & $-.402^{* *}$ & $-.580^{* *}$ & $-.494^{* *}$ & -.093 \\
\hline 1 & Loss of control & $-.258^{*}$ & -.164 & $-.339^{* *}$ & $-.462^{* *}$ & $-.403^{* *}$ & -.051 \\
\hline 2 & Simple perception & $-.360^{* *}$ & $-.299^{*}$ & $-.356^{* *}$ & $-.352^{* *}$ & $-.400^{* *}$ & $-.310^{*}$ \\
\hline 3 & Complex perception & $-.290^{*}$ & $-.307^{*}$ & $-.350^{* *}$ & $-.437^{* *}$ & $-.429^{* *}$ & -.108 \\
\hline 4 & Language & $-.324^{*}$ & $-.338^{* *}$ & $-.278^{*}$ & $-.524^{* *}$ & $-.516^{* *}$ & -.101 \\
\hline 5 & Thought & $-.322^{*}$ & $-.293^{*}$ & $-.341^{* *}$ & $-.499^{* *}$ & $-.343^{* *}$ & -.076 \\
\hline 6 & Memory & $-.359^{* *}$ & -.200 & $-.311^{*}$ & $-.338^{* *}$ & $-.300^{* *}$ & -.113 \\
\hline 7 & Motility & -.239 & -.214 & $-.338^{* *}$ & $-.422^{* *}$ & $-.233^{*}$ & -.076 \\
\hline 8 & Lack of automatism & $-.330^{*}$ & $-.269^{*}$ & -.218 & $-.330^{*}$ & -.283 & .016 \\
\hline 9 & Anhedonia anxiety & -.143 & -.082 & $-.279^{*}$ & $-.384^{* *}$ & $-.220^{*}$ & -.103 \\
\hline 10 & Sensory & -.086 & -.116 & -.164 & $-.287^{*}$ & -.312 & .080 \\
\hline
\end{tabular}

* Correlation is significant at 0.05 level , ** Correlation is significant at 0.01 level

Simple perception, complex perception, thought and lack of automatism correlated with overall perception of health in QOL scale at $\mathrm{p}<0.05$. Almost all the subscales of FCQ-24 correlated negatively with psychological health and psychological relationship except sensory overstimulation which didn't correlate with social relationship. Thus overall FCQ score correlated negatively with physical health, psychological health and social relationship.

\section{DISCUSSION}

In the comparison between bipolar and schizophrenia patients, the phenomenological areas show the widest differences (Table 1). These data confirm those obtained by Ebel et al. (1989) comparing schizophrenia with major affective patients, using the BSABS, Arduini et al. (2002) using Frankfurter BeschwerdeFragebogen (FBF) and Parnas et al. (2003) using Bonn scale for assessment of basic symptoms. It indicates that in schizophrenics, qualitative alterations of the perception of single objects or of some details of objects were more frequent and lasting than in affective patients: a similar pattern was observed for abnormalities of Complex perception. Data about qualitative alterations of perception refer mainly to the vulnerability pattern, which points to perceptive distortions, as being among the predisposing factors for schizophrenia (Ricca et al., 1997), and also emphasizes the necessity of addressing neuropsychological tests towards the areas of the central nervous system involved in these alterations. Thought and language disorders like distinct concentration disorders, thought pressure, thought blocking and thought interference, which can be so pervasive to be dose to the experience of thought influence, seem to be more represented in schizophrenia patients than in bipolar which emphasizes the importance of the alterations of the form of thought processes, as well as delusions, in the clinical characterization of major psychoses (Ricca et al., 1997). From Table 2, the comparison of 


\section{Experience of subjective symptoms in Euthymic Bipolar and remitted Schizophrenia}

the subscale of SCL-90R has been found where the finding was almost similar to the finding by Joe et al. (2008) except that he had not found significant differenceonobsessivecompulsiveand psychoticism. But his finding on psychoticism had shown trend toward higher score in schizophrenia group $(p=0.056)$. This study was also conducted to measure the influence of subjective experiences of bipolar patients and schizophrenia patients on their social adjustment, functioning and quality of life (Table 3 , Table 4 and Table 5). It is thought that subjective symptoms are the result of cognitive impairment (Pallanti et al., 1999) and as because cognitive ability is critical in interpersonal relationships, social skills and social activities, so it was proposed that these experiences might influence one's occupational and social functioning (Joe et al., 2008). Total scores on FCQ correlated negatively with total scores on functional status questionnaire (Table 3) supporting the above proposal that subjective experience might have some influence on patient's functioning. On seeing the subscale wise correlation it can be seen that total FCQ score was not correlated with Basic ADL. It can be explained by the fact that performing daily routine activity does not require much of the physical effort. From Table 4 it is clear that FCQ total score correlated negatively $(\mathrm{p}=0.000)$ with scores on work and social adjustment scale. Our study was further extended to see the effect of subjective symptoms on quality of life WHO-QOL BREF (Table 5). Total FCQ scores correlated negatively with WHO-QOL. Domain wise analysis of WHO-QOL showed that except environmental resources all the domains of WHOQOL were negatively correlated with FCQ total scores. The environment resources were independent of subjective symptoms which can easily be explained as availability of financial and other resources are not dependent on patients' subjective experiences.

\section{CONCLUSION}

In conclusion, it can be said that the schizophrenia group showed higher score on FCQ as compared to bipolar disorders mainly in the areas of perception, thought, language and motility as well as total FCQ scores. When total score on SCL was compared between two groups schizophrenia group showed significantly higher score than bipolar group demonstrating that schizophrenia group was associated with increased level of qualitative anomalous of subjective experiences especially in the domain of cognitive disturbances, perception and motility. These findings suggest that certain anomalies of subjective experience aggregate significantly in schizophrenia when compared with bipolar disorders. As this was the first study which has seen influence of subjective symptoms on social adjustment, functioning and quality of life so more study are needed to conform the findings. Attainment of euthymic/ remitted state may not be sufficient; rather the remission of subjective symptoms should be the target of the treatment. From the above finding it is obvious that subjective symptoms influences a patient's functioning even if they are in their euthymic/remitted state of the illness. So in order to restore premorbid functioning, it may be wise to measure subjective pathology along with objective one which we use very frequently. Expert clinicians could use this information to tailor not only the psychopharmacological but also the psychosocial interventions.

\section{REFERENCES}

Addington, J\&Addington, D. (1999) Neurocognitive and social functioning in schizophrenia. Schizophrenia Bulletin ${ }_{\llcorner}$25(1), 173-82.

Arduini, L., Kalyvoka, A., Stratta, P. et al. (2002) Subjective experiences in schizophrenia and bipolar disorders. European Archives of Psychiatry and Clinical Neuroscience. 252, 24-27.

Cavanagh, J.T., Van, Beck, M., Muir, W. et al. (2002). Case-control study of neurocognitive function in euthymicpatients with bipolar disorder: anassociation with mania. BritishJournal of Psychiatry, 180, 320-326.

Chapman, L. J., Edwell, W. S., Chapman, J. P. (1980) Physical anhedonia, perceptual aberration and psychosis proneness. Schizophrenia Bulletin, 6,639-653.

Ebel, H., Gross, G., Klosterkötter, J. et al.(1989) Basic symptoms inschizophrenic and affective psychoses. Psychopathology, 22, 224-232.

Goldberg, D. \& Williams, P. (1988) A users' guide to the general health qu estionnaire.NFER-NELSON publishing co. ltd. Windsor, Berkshire, UK. 


\section{Experience of subjective symptoms in Euthymic Bipolar and remitted Schizophrenia}

Hofer, A., Baumgartner, S., Bodner, T., et al. (2005) Patient outcomes in schizophrenia II : the impact of cognition. Eur Psychiatry. Aug, 20(5-6), 395-402.

Joel, S., Joo, Y., Kim, S. (2008) Experience of Subjective Symptoms in Euthymic Patients with Bipolar Disorder. Journal of Korean Medical Sciences. 23, 18-23.

Marks, I. (1986) Behavioral psychotherapy Bristol : John Wright (now published by I, Marks Institute of psychiatry, London).

Pallanti, S., Quercioli, L., Pazzagli, A., (1999) Basic symptoms and P300 abnormalities in young schizophrenic patients. Comprehensive Psychiatry, 40, 363-371.
Parnas, J., Handest, P., Sæbye, D., Jansson, L. (2003) Anomalies of subjective experience in schizophrenia and psychotic bipolar illness. Acta Psychiatrica Scandinavica, 108, 126-133.

Ricca, V., Galassi, F., La, Malfa, G. et al.(1997) Assessment of basic symptoms in schizophrenia, schizoaffective and bipolar disorders. Psychopathology, 30, 53-58.

Tsuang, M.T., Woolson, R.F., Fleming, J.A. (1979) Long Term outcome of major psychoses : I Schizophrenia and affective disorders compared with psychiatrically symptom-free surgical conditions. Archives of General Psychiatry. 36, 1295-1301. 